\title{
CHALLENGES WITH OBSTACLE DATA FOR MANNED AND UNMANNED AVIATION
}

\author{
A. Petrovsky $^{1 *}$, M. Doole ${ }^{2}$, J. Ellerbroek ${ }^{2}$, J.M. Hoekstra ${ }^{2}$, F.Tomasello $^{3}$ \\ ${ }^{1}$ Directorate European Civil-Military Aviation, Eurocontrol, 1130, Brussels, Belgium - alexandre.petrovsky@eurocontrol.int \\ ${ }^{2}$ Dept. of Control and Simulation, Faculty of Aerospace Engineering, Delft University of Technology, Delft, The Netherlands - \\ (m.m.doole, j.ellerbroek, j.m.hoekstra)@tudelft.nl \\ ${ }^{3}$ Sciences and Technologies for Air Transport, University Giustino Fortunato, Benevento, Italy; Senior partner of EuroUSC Italia - \\ filippo.tomasello@eurousc-italia.it
}
KEY WORDS: Obstacle data, UTM, U-Space, Aircraft, Drones, Personal air vehicles, Rotorcraft, Helicopters, Aeronautical data quality

\section{ABSTRACT:}

The objective of this paper is to raise awareness about the significance of collecting and ensuring the quality of the obstacle data required for the safety of air navigation for both manned and unmanned aviation. This information could be of importance to geodetic, CityGML, 3D model and Building Information Management (BIM) community. With the advancement of future air mobility concepts such as drones and Personal Air Vehicles (PAVs), there is an increased demand for obstacle data of higher accuracy, including at Very Low Level (VLL) altitude. The paper presents the requirements pertaining to aviation such that the above mentioned communities could understand the existing complexity. This complexity adheres to the aggregation of qualityassured obstacle data from domains outside the aviation field's responsibility. It is expected that with model developments (e.g. BIM), new solutions could be identified to support the aviation community with the aggregation of obstacle data of required quality.

\section{INTRODUCTION}

The advancement of aviation has brought about several advantages such as faster mobility and greater connectivity to air travellers. In 2018 there will be nearly 4 billion air travellers, and this statistic is predicted to almost double to 7.8 billion by 2036 (IATA, 2017). This means that air traffic will increase incessantly in the coming years. It is also expected that new forms of traffic such as drones and Personal Air Vehicles (PAVs) will begin to integrate into our skies in the near future (SESAR, 2018). Our skies are not only becoming more crowded, but also regions of airspace never fully exploited in the past, such as at Very Low Level (VLL) i.e., height not greater than $500 \mathrm{ft}$ above ground level are being 'colonised' by these new applications (Sunil et al., 2015) and (Metropolis, 2015). Therefore, the need for safe air navigation becomes increasingly urgent, also considering that flying closer to the ground means also closer to man-made and natural obstacles.

One element required to enable safer air navigation is the collection and dissemination of high-quality obstacle data. At present, obtaining high-quality obstacle data is subject to many challenges. Therefore, this paper will outline these challenges and the related requirements for both manned and unmanned aviation.

\section{METHODOLOGY}

The methodology adopted in this paper consists of literature and data review (see references), as well as the experience of Eurocontrol, the intergovernmental organisation harmonising the implementation of electronic Terrain and Obstacle Data (eTOD) in Europe. A further analysis is performed on the current and future needs for obstacle data and the difficulties experienced with collection of obstacle data. Finally, several key recommendations are provided for considerations of CityGML/BIM communities.
The remainder of this paper is organized into the following sections. Section 3, outlines all the challenges and requirements concerning obstacle data for civil aviation. Then, in section 4, we discuss the challenges and requirements for manned rotorcraft and also for unmanned aircraft. Lastly, section 5 recaps some of the key aspects of this paper and also outlines future developments in order to tackle challenges posed in this paper.

\section{CHALLENGES WITH OBSTACLE DATA IN CIVIL AVIATION}

\subsection{Requirements for obstacle data provision}

Within the international context of aviation, every State which is member of the United Nations adheres to the Convention on International Civil Aviation (also known as the Chicago Convention) signed in 1944. The 19 Annexes to this Convention promulgated until 2018 contain more than 12,000 international standards and recommended practices (SARPs), all of which have been agreed by consensus by 192 Contracting States of the International Civil Aviation Organisation (ICAO).

Under these SARPS every Member State has a responsibility to oversee the collection, assembly, format and distribution of aeronautical data and information, including obstacles on their respective territory to the international aviation community. This is done to ensure the safety of air operations.

In the European Union this is performed by providers of Aeronautical Information Services (AISP) certified by the competent authority established by the State. 
The role and importance of complete, timely, and accurate aeronautical data and information has changed significantly with the implementation of area navigation (RNAV) ${ }^{1}$ and airborne computer-based navigation systems. This requires improved data quality by validating that information is provided by accountable and qualified data originators through a standard digital data exchange and processing of information and it allows for a timely and accurate distribution of information. Overall, this is reflected in an increased level of safety.

\subsection{Definitions}

An obstacle in aviation denotes an object that is considered a potential hazard to the safe passage of aircraft in different types of operations. The International Civil Aviation Organisation (ICAO), responsible for ensuring uniform standards and practices for flight safety and operations, defines obstacles as follows:

Obstacle: All fixed (whether temporary or permanent) and mobile objects, or parts thereof, that:

a) are located on an area intended for the surface movement of aircraft; or

b) extend above a defined surface intended to protect aircraft in flight; or

c) stand outside those defined surfaces and that have been assessed as being a hazard to air navigation.

The following definitions are provided by ICAO for aeronautical data quality and its characteristics:

Data quality: A degree or level of confidence that the data provided meet the requirements of the data user in terms of accuracy, resolution, integrity.(or equivalent assurance level), traceability, timeliness, completeness and format.

Data accuracy: A degree of conformance between the estimated or measured value and the true value.

Data resolution: A number of units or digits to which a measured or calculated value is expressed and used.

Data integrity (assurance level): A degree of assurance that an aeronautical data and its value has not been lost or altered since the origination or authorized amendment.

Data traceability: The degree that a system or a data product can provide a record of the changes made to that product and thereby enable an audit trail to be followed from the end-user to the originator.

Data timeliness: The degree of confidence that the data is applicable to the period of its intended use.

Data completeness: The degree of confidence that all of the data needed to support the intended use is provided.

Data format: A structure of data elements, records and files arranged to meet standards, specifications or data quality requirements.

1 Area navigation (RNAV) is a method of navigation that permits aircraft operation on any desired flight path within the coverage of station-referenced navigation aids or within the limits of the capability of self-contained aids, or a combination of these.

\subsection{Airborne and ground-based applications using obstacle} data

Obstacle data are used in the following airborne and groundbased applications:

- Ground proximity warning system with forward looking terrain/obstacle avoidance function and minimum safe altitude warning system;

- Determination of contingency procedures for use in the event of an emergency during a missed approach or take-off;

- $\quad$ Aircraft operating limitations analysis;

- Instrument procedure design (including circling procedure);

- Determination of en-route “drift-down" procedure and en-route emergency landing location;

- $\quad$ Synthetic vision systems;

- $\quad$ Flight simulators;

- Advanced surface movement guidance and control system;

- Aeronautical chart production and on-board databases.

\subsection{Analysis of current situation}

3.4.1 Obstacle data chain: Before being uploaded to the avionics' database, the obstacle data undergo a number of steps, as illustrated in Figure 1:

Regulatory framework: Every ICAO Contracting State should have in place a regulatory framework requiring that the erection of any objects penetrating the obstacle collection surfaces set up by ICAO be subject to an authorisation process involving the governmental agency responsible for civil aviation.

Obstacle data origination: The obstacle owner should submit the information about the erected object for assessment and authorisation to the governmental agencies responsible for civil aviation. This information should be provided in accordance with the required format and quality requirements.

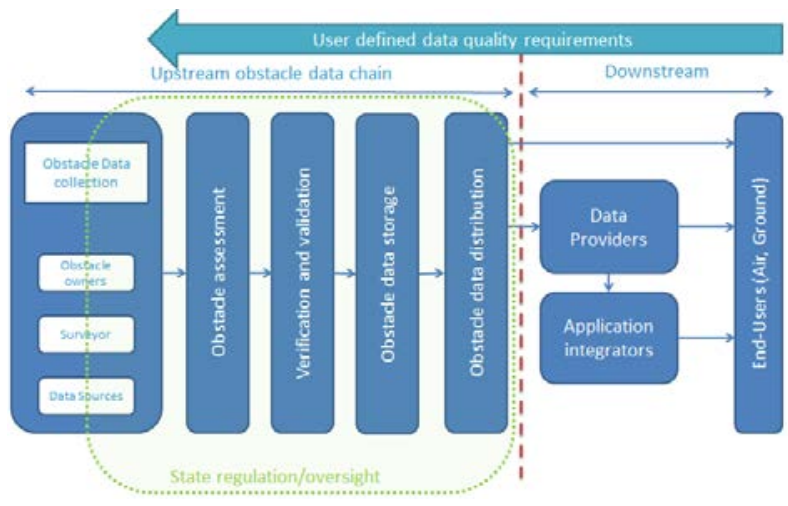

Figure 1. Obstacle data chain (based on EUROCAE ED-76A and Eurocontrol TOD Manual) 
Obstacle assessment and authorisation: the governmental agencies responsible for civil aviation assess the effects of the erected object on the various aviation infrastructures used in air traffic control. For instance: impact of wind turbines on the performance of surveillance systems, object's influence on the electromagnetic radiation of the instrument landing system, penetration of aerodrome protective areas and effect on flight procedures. Following this assessment, the civil aviation agencies either authorize construction and include it in the obstacle register or propose other measures (e.g. change of height, special markings/lighting, etc.).

The above mentioned assessment and authorisation for obstacle construction is required only in the vicinity of the aerodromes (circa 15km) and in the vicinity of radar installation. Otherwise only the notification about the obstacle is required.

Following verification and validation required to ensure that quality requirements are met, the obstacle data is stored in the national obstacle database. Thereafter, the obstacle data are provided via subscription to customers in the form of a dataset, aeronautical information publication (AIP) and charts.

Data providers collect obstacle data from the AIP, dataset and charts of all States world-wide and include them in a database with global coverage. This data is then processed into various airborne applications and then presented in the aircraft cockpit with specific configurations and formats.

\subsection{Obstacle Collection Surfaces}

3.5.1 ICAO specified several obstacle collection surfaces and related quality characteristics. This specification was mostly based on requirements from the applications used in manned fixed-wing aeroplanes (different from rotorcraft and unmanned aviation).

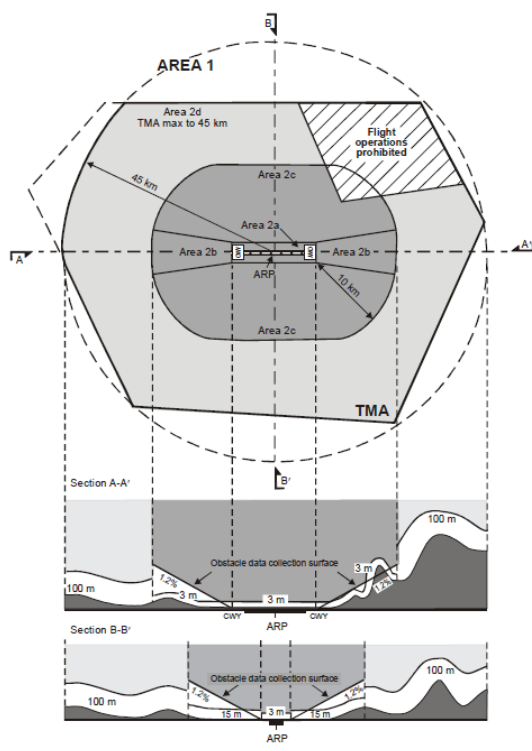

Figure 2. Obstacle data collection surfaces Area 1 and Area 2 (ICAO Annex 15, 2015)
3.5.2 Area 1: the first collection surface in Figure 2 is set up $100 \mathrm{~m}$ above ground level for the whole territory of State. Therefore, all objects higher than $100 \mathrm{~m}$ are considered to be obstacles for aviation and must be assessed and/or authorized by the competent civil aviation government agency. The accuracy of this obstacle data, considering their use in the applications for manned fixed-wing aircraft, is not very high (see Table 1).

\begin{tabular}{|l|l|l|l|l|}
\hline & Area 1 & Area 2 & Area 3 & Area 4 \\
\hline $\begin{array}{l}\text { Vertical } \\
\text { accuracy }\end{array}$ & $30 \mathrm{~m}$ & $3 \mathrm{~m}$ & $0.5 \mathrm{~m}$ & $1 \mathrm{~m}$ \\
\hline $\begin{array}{l}\text { Vertical } \\
\text { resolution }\end{array}$ & $1 \mathrm{~m}$ & $0.1 \mathrm{~m}$ & $0.01 \mathrm{~m}$ & $0.1 \mathrm{~m}$ \\
\hline $\begin{array}{l}\text { Horizontal } \\
\text { accuracy }\end{array}$ & $50 \mathrm{~m}$ & $5 \mathrm{~m}$ & $0.5 \mathrm{~m}$ & $2.5 \mathrm{~m}$ \\
\hline $\begin{array}{l}\text { Confidence } \\
\text { level }\end{array}$ & $90 \%$ & $90 \%$ & $90 \%$ & $90 \%$ \\
\hline $\begin{array}{l}\text { Integrity } \\
\text { classification }\end{array}$ & routine & essential & essential & essential \\
\hline $\begin{array}{l}\text { Maintenance } \\
\text { period }\end{array}$ & $\begin{array}{l}\text { as } \\
\text { require } \\
\mathrm{d}\end{array}$ & $\begin{array}{l}\text { as } \\
\text { required }\end{array}$ & $\begin{array}{l}\text { as } \\
\text { required }\end{array}$ & $\begin{array}{l}\text { as } \\
\text { required }\end{array}$ \\
\hline
\end{tabular}

Table 1. Obstacle data dimensional requirements (ICAO Annex $15,2015)$

3.5.3 Area 2: the required accuracy of obstacle data increases in the vicinity of aerodromes (Area 2). There is a set of various collection surfaces of different shapes and slopes, the most stringent being Areas 2a, 2b, 2c and 2d, as depicted in Figure 2.

3.5.4 Areas 3 and 4: serve the requirements of specific applications mostly for fixed-wing aircraft and are located within aerodrome boundaries.

\subsection{Feature capture rules and geometry type}

3.6.1 Geometry type: the defined spatial extent of an obstacle should be captured as a feature into the database and rules are set up for defining their geometry (point, line, polygon). This is defined based on the obstacle area in which they are located. A proposal for feature capture rules has been developed on the basis of the Open Geospatial Consortium (OGC) definitions for 3D models in the CityGML specification document. As such, Level of Detail LOD2 'differentiated roof structures and thematically differentiated surfaces. Vegetation objects may also be represented' was used (see Table 2).

\begin{tabular}{|l|l|l|l|l|}
\hline & LODO & LOD1 & $\underline{\text { LOD2 }}$ & $\underline{\text { LOD3 }}$ \\
\hline Scale description & $\begin{array}{l}\text { regional, } \\
\text { landscape }\end{array}$ & city, region & $\begin{array}{l}\text { city districts, } \\
\text { projects }\end{array}$ & $\begin{array}{l}\text { architectural } \\
\text { models } \\
\text { (outside) }\end{array}$ \\
\hline Class of accuracy & lowest & low & middle & high \\
\hline $\begin{array}{l}\text { Absolute 3D point } \\
\text { accuracy (position } \\
\text { / height) }\end{array}$ & $\begin{array}{l}\text { lower than } \\
\text { LOD1 }\end{array}$ & $5 / 5 \mathrm{~m}$ & $2 / 2 \mathrm{~m}$ & $0.5 / 0.5 \mathrm{~m}$ \\
\hline Generalisation & $\begin{array}{l}\text { maximal } \\
\text { generalisation } \\
\text { (classification } \\
\text { of land use) }\end{array}$ & $\begin{array}{l}\text { object blocks } \\
\text { as generalised } \\
\text { features; }> \\
6^{*} 6 \mathrm{~m} / 3 \mathrm{~m}\end{array}$ & $\begin{array}{l}\text { objects as } \\
\text { generalised } \\
\text { features; }> \\
4^{*} 4 \mathrm{~m} / 2 \mathrm{~m}\end{array}$ & $\begin{array}{l}\text { object as real } \\
\text { features; }> \\
2^{*} 2 \mathrm{~m} / 1 \mathrm{~m}\end{array}$ \\
\hline $\begin{array}{l}\text { Building } \\
\text { installations }\end{array}$ & - & - & - & $\begin{array}{l}\text { representative } \\
\text { exterior effects }\end{array}$ \\
\hline Roof form/structure & none & flat & $\begin{array}{l}\text { roof type and } \\
\text { orientation }\end{array}$ & real object form \\
\hline
\end{tabular}

Table 2. Specification of LOD in (CityGML, 2008) 
In line with these specifications, thresholds were established based on the required horizontal accuracy within the specific collection surface area. The minimum dimension of an obstacle to be depicted as a polygon would be at the intersection with the collection surface:

- $\quad$ Area 1: $100 \times 100 \mathrm{~m}$;

- Area 2: $10 \times 10 \mathrm{~m}$;

- Area 3: $1.0 \times 1.0 \mathrm{~m}$;

- Area 4: 5.0 x 5.0m.

If only one of the dimensions exceeds these values then the obstacle should be represented as a line. If none of the dimensions are exceeding these values then it should be represented as a point. In air navigation, three different types of obstacles exist which include:

- Point obstacles, e.g. masts, antennas, etc.

- Line obstacles, e.g. high-voltage cables, cable installations, etc.

- Polygon obstacles, e.g. buildings, large vegetation area, etc.

3.6.2 Feature capture rules: an obstacle comprises one or more parts or vertices. For each part of an obstacle, various geometric characteristics can be recorded, such as the elevation of the obstacle and its coordinates. For an obstacle in addition to its geometrical type, its horizontal dimensions can also be recorded (horizontal extent e.g. for helices of wind turbine or guy wires of a mast).

For each obstacle, specific basic information is recorded. Each obstacle is allocated a predefined obstacle type (AIXM ${ }^{2}$ model) and corresponding information about markings and lighting, etc. In addition, quality assurance data, information concerning the data originator, data sources, obstacle identifier, etc., are captured. The complete list of obstacle attributes is represented in Table 3.

\begin{tabular}{|l|c|}
\hline Obstacle attribute & Mandatory/Optional \\
\hline Area of coverage & Mandatory \\
\hline $\begin{array}{l}\text { Data originator } \\
\text { identifier }\end{array}$ & Mandatory \\
\hline Data source identifier & Mandatory \\
\hline Obstacle identifier & Mandatory \\
\hline Horizontal accuracy & Mandatory \\
\hline $\begin{array}{l}\text { Horizontal confidence } \\
\text { level }\end{array}$ & Mandatory \\
\hline Horizontal position & Mandatory \\
\hline Horizontal resolution & Mandatory \\
\hline Horizontal extent & Mandatory \\
\hline $\begin{array}{l}\text { Horizontal reference } \\
\text { system }\end{array}$ & Mandatory \\
\hline Elevation rendatory \\
\hline Height & Optional \\
\hline Vertical accuracy & Mandatory \\
\hline $\begin{array}{l}\text { Vertical confidence } \\
\text { level }\end{array}$ & Mandatory \\
\hline Vertical resolution & Mandatory \\
\hline $\begin{array}{l}\text { Vertical reference } \\
\text { system }\end{array}$ & Mandatory \\
\hline Obstacle type & Mandatory \\
\hline Geometry type & Mandatory \\
\hline
\end{tabular}

\footnotetext{
${ }^{2}$ AIXM - Aeronautical Information Exchange Model
}

\begin{tabular}{|l|l|}
\hline Integrity & Mandatory \\
\hline Date and time stamp & Mandatory \\
\hline $\begin{array}{l}\text { Unit of measurement } \\
\text { used }\end{array}$ & Mandatory \\
\hline Operations & Optional \\
\hline Effectively & Optional \\
\hline Lighting & Mandatory \\
\hline Marking & Mandatory \\
\hline
\end{tabular}

Table 3. Obstacle attributes (ICAO Annex 15, 2015)

The Aeronautical Information Exchange Model (AIXM) version 5.1 (AIXM, 2018) is used in aviation for management and exchange of aeronautical data in digital format. This presentation of obstacle data is based on Geography Markup Language (GML). The GML format is one of the application schemas that is applicable in the Aeronautical domain.

3.6.3 Complex obstacles and segmentation: occasionally, several obstacles are contiguous or are of complex shape. In such circumstances it is more logical to split the obstacles into different segments to allow a simpler representation. Additional difficulties appear with the representation of objects whose footprint above the collection surface varies with growing height (trees, tilted roofs, on-top structures, nested buildings, roof-mounted antennae, masts with guy wires e.g. Figure 3). The application of segmentation may offer significant benefits where the height of the object may negatively impact operations. However, given the additional cost of recording obstacles using segmentation, careful consideration is needed from the operational perspective to ensure that these costs are justified.

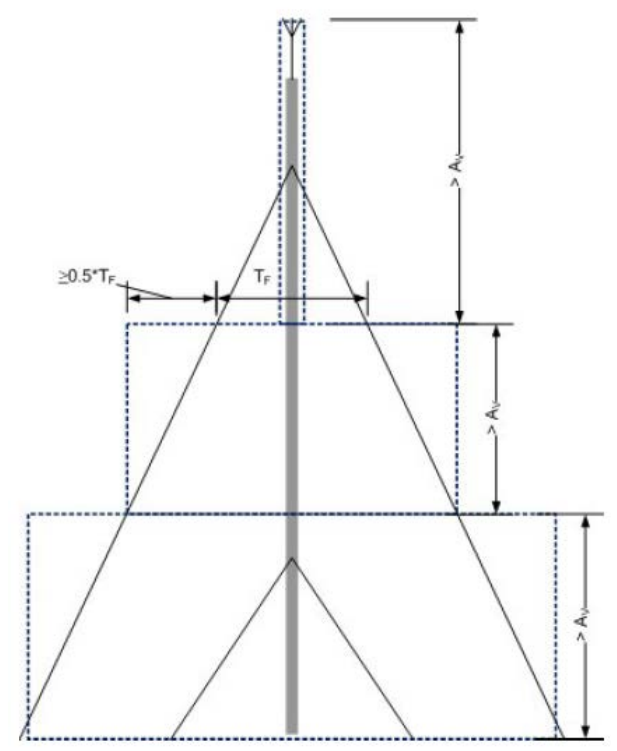

Figure 3. Vertical segmentation of antenna based on footprint and vertical accuracy (Eurocontrol TOD Manual, page 197, 2015)

\section{CHALLENGES WITH OBSTACLE DATA FOR NOVEL APPLICATIONS}

Novel applications and operations are developing that require a higher level of detail and accuracy for obstacle data. 


\subsection{Rotorcraft}

The main civil helicopter operations include:

- Emergency Medical Services (EMS) - e.g. ambulances, carrying sick or injured people as fast as possible from a known location to the hospital;

- $\quad$ Search and Rescue (SAR) - similar to EMS, but the location of the sick or injured people is unknown and needs to be established. The EMS and SAR often operate in challenging environments such as degraded weather conditions or mountainous areas;

- Private and business transportation, which operates similarly to person transportation with a fixed-wing aircraft, i.e., taking people from an aerodrome, performing en-route flight and landing at another aerodrome;

- Offshore transportation, which is similar to private and business transportation but is operated from offshore locations, e.g. oil and gas platforms;

- Law enforcement - use of helicopters by the police and special forces which are flying very close to the ground and mostly in urban areas;

- Aerial work - all works related to buildings and maintenance in locations with difficult access, e.g. mountainous areas.

In normal weather and visibility conditions, a light or mediumsized helicopter operates for transit over land or sea between 300 and $1500 \mathrm{~m}$ above ground level (AGL) at a speed of 220$280 \mathrm{~km} / \mathrm{h}$. For surveillance or SAR activities, it operates between 10 and $600 \mathrm{~m}$ AGL and at less than $150 \mathrm{~km} / \mathrm{h}$.

In degraded weather or/and visibility conditions when lowaltitude clouds cover flat terrain or sea the helicopters need to fly below the clouds at a lower altitude and/or need to lower their altitude to maintain visual contact with the ground. In some cases they need to land as soon as possible or turn back to try to find better conditions.

According to various studies, the majority of incidents and accidents with helicopters are due to inadequate consideration by the pilot of obstacles or terrain, or are related to the pilot's insufficient awareness of non-detected obstacles, insufficient ground visibility, difficult terrain, or hoist/sling relation with ground obstacles. Therefore, improving helicopter pilot awareness on terrain and obstacles would help to improve safety.

Modern helicopters are equipped with an avionic suite that includes on their displays the graphical representation of various information layers. Such layers include: position relative to the terrain, digital maps with topographic elevation, and obstacle depiction - which in the event of close terrain or obstacles raise aural and visual caution/warning alerts for pilots to change direction in order to avoid collision with the ground or obstacles.

Requirements for data: the current information on obstacles provided by the AISPs outside aerodrome areas are insufficient for helicopter operations in terms of accuracy and collection surfaces.

Based on helicopters' operational needs and mission-function performances, they would require data on all obstacles higher than $60 \mathrm{~m}$ with a vertical accuracy of $7 \mathrm{~m}$ and a horizontal accuracy of $16 \mathrm{~m}$ anywhere in the territory, even far from aerodromes, as required by several types of helicopter operations.

\subsection{Drones and Personal Air Vehicles}

The demand for civil unmanned aviation operations such as leisure and commercial purpose drones, and Personal Air Vehicles (PAVs) has steadily increased over the last ten years. This happens because these emerging mobility concepts have the potential to generate significant economic growth (SESAR, 2017) and to bring about positive environmental impact to urban cities in the future (Stolaroff et al., 2018). Recent studies indicate that by 2050 there will be 400,000 drones operating at a VLL altitude of $500 \mathrm{ft}$ AGL in Europe's skies (SESAR, 2017). This constitutes to a high-density of autonomous drone operations.

To contribute to promoting the development of these new services, the research body for Air Traffic Management (ATM) in Europe, SESAR ${ }^{3}$, is developing an Unmanned Traffic Management (UTM) system for Europe. This UTM system for Europe, known as U-Space, is an amalgamation of a number of services. To enable such a system, U-Space envisages several key actors and service providers as illustrated in Figure 4. One of the key elements which is relevant to this paper, is the service provider of obstacle information, which is beyond the scope of current services in ICAO Annex 15, since drones and PAVs do not normally fly in aerodromes, but instead in obstacle-rich urban environments relatively far from aerodromes and below the altitude with services that protect manned fixed-wing aeroplanes.

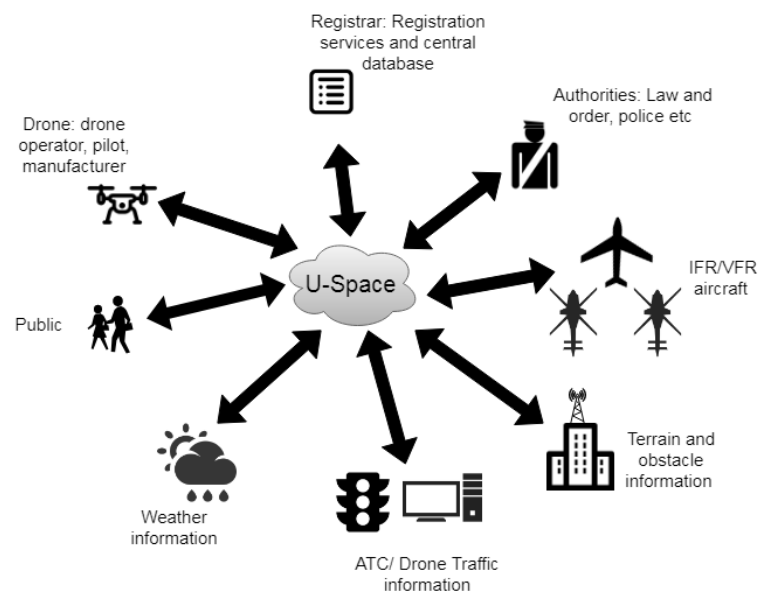

Figure 4. Visual representation of U-Space

Instead, it is envisioned that drones and PAVs will conduct a wide range of missions ranging from spraying pesticides on crops to delivering packages in dense urban environments. Similarly, on-demand ridesharing company, Uber, announced plans to launch flying taxis on their high-density routes in order to curb traffic congestion in urban environments (Hawkins, 2018).

The degree of obstacle information will vary with the type of mission. For instance, drones employed for pesticide spraying will operate in a rural environment in which the presence of obstacles will be minimal. Delivery drones, on the other hand,

\footnotetext{
${ }^{3}$ Single European Skies ATM Research
} 
will operate in complex urban environments autonomously and in Beyond Visual Line-of-Sight (BVLOS ${ }^{4}$ ) conditions. These delivery drones will need to ascend/descend in very close proximity to a large number of man-made structures such as buildings, cell-towers, and high-voltage electrical power cables. The above flight phase of ascend/descend will take place below the notional $50 \mathrm{ft}$ predominately in an urban landscape which makes this phase the most challenging for autonomous drones (Krishnakumar et al., 2017) and (Kopardekar et al., 2016). Drones therefore will operate amongst man-made static structures as well as dynamic obstacles such as automobiles, and this dynamic aspect increases with the level of detail.

Recent studies claim that the above challenges of autonomous drones navigating in a complex urban landscape could be alleviated by using the notion of geofencing (Stevens \& Atkins, 2018). A geofence is basically a virtual 3-dimensional boundary on a geometrical area that restricts access to drones (Stevens \& Atkins, 2018). Geofences are usually defined around man-made structures (obstacle) to create No-Fly-Zones (NFZs). Mathematically, a geofence, $g$, can be defined by (Stevens \&Atkins):

$$
g=\left\{n, v[], z_{f}, z_{c}, m, h_{i}[], i d s[]\right\}
$$

where $n=$ number of horizontal vertices

$v=$ horizontal vertices

$Z_{f}=$ minimum floor altitude

$Z_{c}=$ maximum ceiling altitude

$h=\left(\varphi_{i}, \lambda_{i}, z_{i}, t_{i}\right)$

$\varphi_{i}=$ latitude coordinates

$\lambda_{i}=$ longitude coordinates

$Z_{i}=$ altitude of geometrical area above mean sea level

$t_{i}=$ geofence activation time

$i d s=$ unique identification numbers

I ne geotence boundaries in equation ( 1 ) are detıned in meters relative to the obstacle surface.

A geofence/NFZ possesses the ability to increase the safety of the drone as well as to third party property. Popular autonomous drone systems offer NFZs information over critical areas such as aerodromes, governmental buildings and nature reserves. This NFZ information is programmed in the drone's autopilot. Moreover, NFZs can be static or dynamic in nature i.e., the geospatial boundaries of the geofence can be timevarying. For example, a dynamic geofence is usually defined around a stadium while a static geofence is defined around an airport. The geofencing capability is an integral element of USpace. However, to define such geofences, accurate geometrical data on the obstacles are required.

The notion of geofencing can also be employed as a design element in developing the airspace for drone and PAV operations. Geofencing can be used to define virtual "corridors" in order to guide these vehicles to their destinations. Notably, for high-density traffic situations, geofencing is utilized for geovectoring $^{5}$ in order to manage the airspace capacity (Hoekstra et al., 2018).

${ }^{4}$ Beyond Visual Line Of Sight or BVLOS, means flying a drone beyond the respective pilot's visual line of sight.

${ }^{5}$ Geovectoring is a protocol for improving the safety of air navigation for autonomous drones and PAVs in high-density traffic scenarios. Geovectoring applies 3-dimensional speed restrictions for all drones/PAVs enclosed by a geofence.
Therefore, detailed information on obstacles will be required to effectively design the (urban) airspace, and execute high-density drone missions in urban environments.

Requirements for data: the unmanned aviation concepts require high-quality obstacle information in order to execute a safe flight. As drones are constrained to fly at VLL altitudes, therefore the obstacle data needs to be within $1 \mathrm{~m}$ accuracy (both vertical and horizontal) with a one meter resolution provided with a confidence level of 95 percent. This level of resolution of obstacle data will enable geofencing to be implemented more effectively. In addition, it will also enable Furthermore, a higher accuracy and will enable maximum utilization of the given airspace. In contrast to manned aviation, assessment and authorization of obstacles are not required. Drones and PAVs require obstacle information with respect to: position of obstacles, height of obstacles and the type of obstacle.

\section{FURTHER DEVELOPMENTS AND CONCLUSIONS}

At present, the provision of obstacle data for manned aviation satisfying all quality requirements is an enormous challenge for many States and traditional AIS providers in Europe. It is in particular linked to the fact that many of these obstacles are originated outside the aviation domain. As a result, this requires the establishment and maintenance of a regulatory framework at the inter-governmental level within each State with clear description of roles and responsibilities.

The requirements emanating from new applications (rotorcraft, drones, PAVs) bring an additional challenge which will be hard to be embraced at the State level using the existing method for collection obstacle data. Therefore, new methods have to be explored, including for oversight of related service providers.

With the integration of standards used for Building Information Modelling (BIM) with GIS standards, in applications such as CityGML, it would be of interest for CityGML/BIM community to consider the needs of aviation in obstacle data for new applications. Some new methods for ensuring the collection of obstacle data while ensuring the required data quality would be expected.

\section{REFERENCES}

Aeronautical Information Exchange Model (AIXM), 2018. AIXM 5.1/5.1.1, http://aixm.aero/page/aixm-51-511 (5 July 2018).

Aeronautical Information Exchange Model AIXM 5.1.1. Data Type - - CodeVerticalStructureType, http://aixm.aero/sites/aixm.aero/files/imce/AIXM511HTML/AI XM/DataType_CodeVerticalStructureType.html (5 July 2018).

Airbus Defence \& Space, November 2014. TOD Requirements for Helicopter Operations, Eurocontrol TOD WG/17.

Airbus Helicopters, November 2014. Databases usage for Helicopters, Eurocontrol TOD WG/19.

Austro Control GmbH / ITV Consult, August 2014. Datenproduktspezifikation für Luftfahrthindernisse in Österreich.

Fundamentally, geovectoring reduces chaos by mitigating collision conflicts between drones or PAVs. 
Commission Implementing Regulation (EU) 2017/373 of 1 March 2017 laying down common requirements for providers of air traffic management/air navigation services and other air traffic management network functions and their oversight, repealing Regulation (EC) No 482/2008, Implementing Regulations (EU) No 1034/2011, (EU) No 1035/2011 and (EU) 2016/1377 and amending Regulation (EU) No 677/2011.

COMMISSION REGULATION (EU) No 73/2010 of 26 January 2010. laying down requirements on the quality of aeronautical data and aeronautical information for the single European sky.

Eurocontrol, 2015, EUROCONTROL Terrain and Obstacle Data Manual (TOD), Edition: 2.1.

Eurocontrol, 2014, EUROCONTROL Guidelines How to Assess the Potential Impact of Wind Turbines Surveillance Sensors, Edition: 1.2

Hawkins, A, J., 2018. Uber to Open Advanced Technologies Centre In Paris Focused On Flying Taxis, the Verge, https://techcrunch.com/2018/05/09/ubers-aerial-taxi-play/ (2 July 2018).

Hoekstra, J, M., Ellerbroek, Sunil, E., Maas, J., 2018. Geovectoring: Reducing Traffic Complexity to Increase the Capacity of UAV airspace, International Conference for Research in Air Transportation, ICRAT, Barcelona, Spain.

IATA, 2017. 2036 Forecast Reveals Air Passengers Will Nearly Double to $7.8 \quad$ Billion, http://www.iata.org/pressroom/pr/Pages/2017-10-24-01.aspx (2 July 2018).

ICAO, July 2016. Annex 15 to the Convention on International Civil Aviation, Aeronautical Information Services, $15^{\text {th }}$ Edition.

ICAO, July 2009. Annex 4 to the Convention on International Civil Aviation, Aeronautical Charts, $11^{\text {th }}$ Edition.

ICAO, 2008. Doc 9613: Performance-based Navigation (PBN) Manual, $3^{\text {rd }}$ Edition.

ICAO, 2015. ICAO EUR DOC 015: European guidance material on managing building restricted areas, $3^{\text {rd }}$ Edition.

Kopardekar, P., Rios, J., Prevot, T., Johnson, M., Jung, J., and Robinson III, J, E., 2016. Unmanned Aircraft System Traffic Management (UTM) Concept Of Operations. American Institute of Aeronautics and Astronautics, AIAA. Washington D.C, USA.

Krishnakumar, K., Kopardekar, P., Ippolito, C., and Melton, J., 2017. Safe Autonomous Flight Environment (SAFE50) for The Notional Last " $50 \mathrm{ft}$ " of Operations of " $55 \mathrm{lb}$ " Class of UAS. AIAA SciTech, Grapevine, TX, USA.

Metropolis, 2015. Metropolis Project, Delft University of Technology https://homepage.tudelft.nl/7p97s/Metropolis/ (10 July 2018).

OGC City Geography Markup Language (CityGML), August 2008. Encoding Standard, Version 1.0.0.

SESAR, 2017. U-Space Blueprint Document https://www.sesarju.eu/sites/default/files/documents/reports/Uspace\%20Blueprint\%20brochure\%20final.PDF (1 July 2018).
Stolaroff, J., Samaras, C., O’Neill, E, R., Lubers, A., Mitchell, A,S., and Ceperley, D., 2018. Energy Use and Life Cycle Greenhouse Gas Emissions of Drones for Commercial Package Delivery, Nature, doi.org/10.1038/s41467-017-02411-5.

Stevens, M, N., and Atkins, E, M., 2018. 'Geofencing In Immediate Reaches Airspace for Unmanned Aircraft System Traffic Management'. In AIAA SciTech, Kissimmee, Florida, USA.

Sunil, E., Hoekstra, J., Ellerbroek, J., Bussink, F., Nieuwenhuizen, D., Vidodavljevic, A., and Kern, S., 2015. Metropolis: Relating Airspace Structure and Capacity for Extreme Traffic Densities, $11^{\text {th }}$ FAA/Eurocontrol ATM Seminar, Lisbon, Portugal.

The European Organisation for Civil Aviation Equipment EUROCAE ED-76A, June 2015. Standards for processing aeronautical data.

The European Organisation for Civil Aviation Equipment EUROCAE ED-98C, October 2015. User requirements for terrain and obstacle data. 